This is the final peer-reviewed accepted manuscript of:

Bruni, S., Rebischung, P., Zerbini, S. et al. Assessment of the possible contribution of space ties on-board GNSS satellites to the terrestrial reference frame. Journal of Geodesy 92, 383-399 (2018).

The final published version is available at: https://doi.org/10.1007/s00190-017$\underline{1069-z}$

Rights / License:

The terms and conditions for the reuse of this version of the manuscript are specified in the publishing policy. For all terms of use and more information see the publisher's website. 


\title{
Assessment of the possible contribution of space ties on-board GNSS satellites to the terrestrial reference frame
}

\author{
Sara Bruni ${ }^{1}$ - Paul Rebischung ${ }^{2}$ - Susanna Zerbini ${ }^{1} \cdot$ Zuheir Altamimi $^{2}$. \\ Maddalena Errico $^{1}$ - Efisio Santi ${ }^{1}$
}

\begin{abstract}
The realization of the international terrestrial reference frame (ITRF) is currently based on the data provided by four space geodetic techniques. The accuracy of the different technique-dependent materializations of the frame physical parameters (origin and scale) varies according to the nature of the relevant observables and to the impact of technique-specific errors. A reliable computation of the ITRF requires combining the different inputs, so that the strengths of each technique can compensate for the weaknesses of the others. This combination, however, can only be performed providing some additional information which allows tying together the independent technique networks. At present, the links used for that purpose are topometric surveys (local/terrestrial ties) available at ITRF sites hosting instruments of different techniques. In principle, a possible alternative could be offered by spacecrafts accommodating the positioning payloads of multiple geodetic techniques realizing their co-location in orbit (space ties). In this paper, the GNSS-SLR space ties on-board GPS and GLONASS satellites are thoroughly examined in the framework of global reference frame computations. The investigation focuses on the quality of the realized physical frame parameters. According to the achieved results, the space ties on-board GNSS satellites cannot, at present, substitute terrestrial ties in the computation of the ITRF. The study is completed by a series of synthetic simulations investigating the impact that substantial improvements in the volume and quality of SLR observations to GNSS satellites would have on the precision of the GNSS frame parameters.
\end{abstract}

Keywords Space ties · SLR · GNSS · ITRF · Origin · Scale

\section{Introduction}

The Earth is a complex interconnected system which continuously evolves over time. Geophysical phenomena span a wide range of spatial and temporal scales and typically involve different geospheres. Advances in Earth sciences, then, necessarily rely on the availability of a unique framework supporting the consistent study of the system as a whole. Thanks to the efforts and the cooperation of a number of geodetic institutions and associations, such a framework is nowadays provided by the international terrestrial reference system (ITRS) and by its associated materialization, the international terrestrial reference frame (ITRF). Supplying "the foundation for nearly all ground-based and space-based observations" (Minster et al. 2010), the availability of an accurate and stable ITRF enables a multi-technique approach in the monitoring of geophysical processes. In addition, it allows tying together data acquired in successive measuring campaigns (Nerem et al. 2010), which is a fundamental requirement for the reliable detection of slow movements and subtle crustal deformations (Blewitt 2015). In 2015, the General Assembly of the United Nations has recognized the key role of accessible, accurate and long-term stable reference frames in sustainable development policymaking and in the assessment of global change studies (General Assembly of the United Nations 2015, resolution 69/266).

$\triangle$ Sara Bruni

sara.bruni4@unibo.it

1 DIFA Dipartimento di Fisica e Astronomia, University of Bologna, Bologna, Italy

2 Laboratoire de Recherche en Géodésie (LAREG), Institut National de l'Information Géographique et Forestière (IGN), Paris, France 
Scientific studies focusing on sea level changes, variations in ice sheet thickness, ground subsidence, hydrological forcing, pre-seismic strain accumulation and visco-elastic characterization of Earth interior from post-seismic deformation pose the most stringent requirements on the realization of the reference frame (Blewitt et al. 2010; Blewitt 2015). All these disciplines critically depend on the accurate materialization of the ITRF fundamental parameters, namely its origin and its scale, and of their variations over time. Inaccurate determinations of such quantities, in fact, might mask or bias the detection of subtle geophysical signals.

The actual computation of the ITRF is based on the data acquired by four different space geodetic techniques, namely the Satellite Laser Ranging (SLR), the Very Long Baseline Interferometry (VLBI), the Global Navigation Satellite Systems (GNSS) and the Doppler Orbitography Radiopositioning Integrated by Satellite (DORIS) (Altamimi et al. 2016). When treated independently, each of these techniques realizes its proper frame (i.e., origin and scale). The quality of the resulting parameters varies according to the observation principle and to the impact of systematic biases on the acquired observations. The combination of different techniques aims at compensating specific limitations and drawbacks with the strengths of the other contributions. The different technique networks are, however, independent from one another, and their reciprocal spatial distribution has to be established in order to perform the inter-technique combination. For such connection to be evaluated, it is necessary that the different geodetic systems are co-located within a distance that can be measured with independent high precision strategies.

At present, the inter-technique link is provided by terrestrial (or local) ties, which are measurements of the distances and of the angles between the reference points (RPs) of different instruments, co-located at some ITRF sites. According to Altamimi et al. (2011), the precision of terrestrial tie estimates is, in general, not better than $3 \mathrm{~mm}$. Concerning the accuracy, ITRF2014 results show that the 3D agreement between terrestrial ties and the corresponding space geodetic estimates is worse than $2 \mathrm{~cm}$ in $20 \%$ of the cases. Moreover, differences larger than $5 \mathrm{~mm}$ are found for at least one component for about $70 \%$ of the surveyed ties. Such discrepancies result from calibration issues and systematic errors potentially affecting all the involved measurements. Evidences listed in Altamimi et al. (2011), however, suggest that the major contributors are likely to be the systematic biases associated with space geodetic estimates. A detailed discussion of the technical aspects of local surveys and of their implications for the realization of terrestrial reference frames can be found in Sarti et al. (2013).

In this context, Thaller et al. (2011) suggested that a complementary validation of terrestrial links could be provided by the so-called space ties. Some spacecrafts, in fact, accom- modate positioning payloads of different techniques, and their orbit can be estimated through the simultaneous adjustment of the different data types. Besides validation purposes, the co-location in space would in principle overcome some of the most problematic aspects of terrestrial ties, namely their inhomogeneous spatial distribution and the suboptimal frequency of their updates. Terrestrial ties, in fact, can only be evaluated at those ITRF sites where instruments of the different techniques are co-located and their values are just rarely revisited because of the costs associated with the required surveying campaigns. In the space-tie approach, on the contrary, all the different observations to a certain satellite can be gathered in the same adjustment encompassing orbit parameters and ITRF products. The inter-technique link is then realized continuously, and every station of the observing networks may contribute in its realization. The reliability of the link "in orbit," however, shall be investigated against some critical aspects related to its actual implementation. First of all, accurate pre-launch calibrations of the center of mass $(\mathrm{CoM})$ offsets of the different positioning payloads are lacking for multi-technique spacecrafts, limiting the capability of achieving a high-quality link. In addition, abundance and quality of the technique-specific observations play a major role in the effectiveness of the ties. Sparse and noisy observations might be insufficient to perform a connection accurate enough to transfer reference frame information between the different techniques.

This study aims at answering the question whether the colocation between the GNSS and SLR techniques on-board GNSS satellites can replace the use of terrestrial ties in the computation of the ITRF. The analysis focuses on the characterization of the precision, accuracy and pertinence of the derived combined frame parameters. The investigation is carried out for both short- and long-term terrestrial frames.

The data selected for this study are presented in Sect. 2, while the devised analysis strategies are detailed in Sect. 3. The procedures adopted for treating GNSS and SLR observations, as well as the inter-technique combination scheme, are illustrated in separate subsections. The achieved results are presented and discussed in Sect. 4, where the outcomes of the short- and long-term computations are shown. A fifth section reports the findings of a synthetic study investigating the effects of improvements in SLR tracking performances. Finally, all the relevant conclusions are summarized in Sect. 6.

\section{Input data}

Three different types of data were taken into account for this study: GNSS measurements acquired by ground stations and SLR observations to the LAGEOS and to the GNSS (GPS and GLONASS) satellites. The first two groups are 


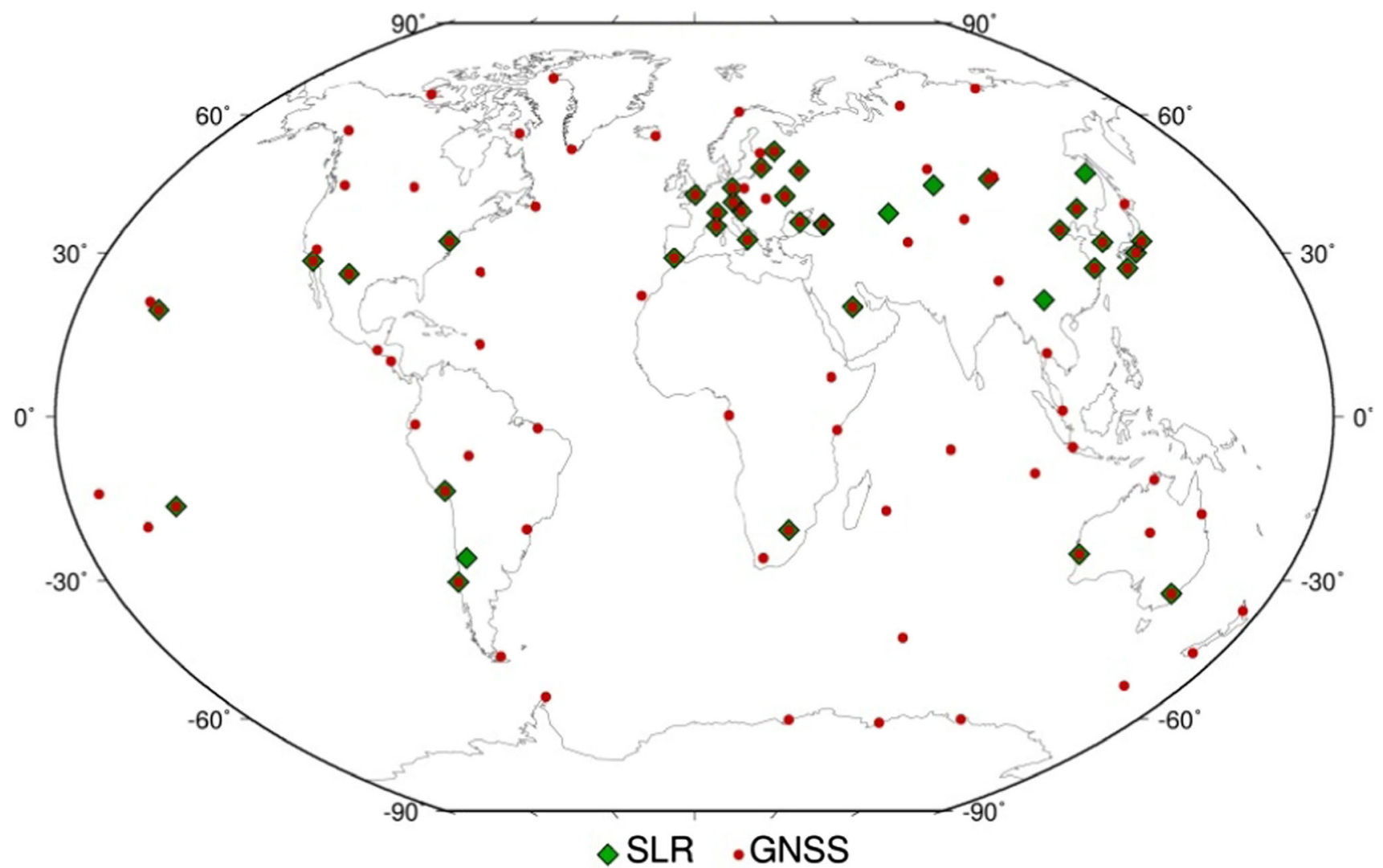

Fig. 1 Selected ground network. All active SLR sites (green squares) were included together with their co-located GNSS antennas (red dots). The GNSS network was completed by a set of stations homogeneously distributed over the globe

long-established inputs for the ITRF computation, while the last one is needed to actually enable the combination following the space-tie approach. The investigated link was mainly realized by GLONASS satellites, and all equipped with Laser Retroreflector Arrays (LRA) and therefore trackable by SLR ground stations; for the GPS constellation only two spacecrafts (GPS-35 and GPS-36) provided a contribution. Concerning microwave data, on the other hand, the observations from all GPS and GLONASS satellites were included in the solution.

The processing focused on a 4-year interval starting in 2011, when the Russian GLONASS constellation was fully restored. The selected network is reported in Fig. 1; it encompasses 104 GNSS antennas and 39 SLR stations, part of the International GNSS Service (IGS) and of the International Laser Ranging Service (ILRS) networks, respectively (Dow et al. 2009; Pearlman et al. 2002). All SLR sites active in the course of the years from 2011 to 2014 were included, together with their co-located GNSS instruments. During the investigated period, only 5 ITRF sites hosting an SLR telescope were not equipped with an operative GNSS antenna. As the spatial distribution of SLR stations was highly inhomogeneous, a set of complementary GNSS stations was added in order to improve the global coverage provided by that technique. In the site selection process, priority was given to stations that observed continuously over the chosen time period and to GLONASS capable stations. The number of stations which could track GLONASS satellites increased from about 50 to $80 \%$ of the total network size between the beginning of 2011 and the end of 2014.

\section{Methodology}

All measurements described in Sect. 2 were processed with the same software package, Bernese GNSS software v5.2 (Dach et al. 2015), ensuring the highest possible consistency in data treatment. For each group of observations, normal equation systems (NEQs) were derived independently to serve as basis for the subsequent reference frame computations. In order to access the full reference frame information inherent in the available observations, it is necessary to simultaneously set up all the parameters from which the technique-specific observable depends. If some of these quantities are kept fixed to their a priori values, in fact, the external reference frame in which they are expressed will be aliased, to some extent, in the new realization. Thus, for each group of observations, the data adjustment encompassed sta- 
tion coordinates, satellite orbit parameters, Earth orientation parameters (EOPs) and technique-specific corrective terms absorbing systematic errors and the effects of mismodeling issues. Among these nuisance parameters, the most relevant elements for the study at hand are the Laser Ranging Array (LRA) offsets and the phase center offsets (PCOs) of GNSS satellites. Such quantities express the eccentricity vectors of the different positioning payloads with respect to the satellite center of mass (CoM), to which orbital elements are referred. The vectorial sum of LRA and PCO constitutes the properly said "space tie" (Thaller et al. 2011), as these quantities connect, via the satellite CoM, the reference points of the different geodetic systems on-board the same platform. In addition, for the SLR technique, it was necessary to account for range biases (RBs), which represent the station- and satellite-dependent difference between the theoretical and the measured range (Thaller 2008). Finally, the analysis accounted for delays introduced by the signal propagation through the atmosphere. According to the recommendations of the relevant services of the International Association of Geodesy (IAG), namely the IGS and the ILRS, such delays were estimated as explicit parameters for GNSS data, but modeled with an appropriate mapping function for SLR observations.

The analysis of GNSS data and SLR observations to LAGEOS satellites followed protocols and recommendations issued in the framework of the ITRF2014 reprocessing campaigns (IGS repro2 campaign guidelines can be found at http://acc.igs.org/reprocess2.html; ILRS prescriptions are listed in the minutes of the Analysis Working Group (AWG) meetings, http://ilrs.gsfc.nasa.gov/about/ reports/meeting_reports.html of the years 2013-2014). As indicated in the ITRF2014 call for participation, such solutions must conform to the International Earth Rotation and Reference System Service (IERS) Conventions 2010 (Petit and Luzum 2010), including updates posted at the relevant Web site (IERS Conventions Center 2015).

The analysis procedure adopted for each group of observations is detailed in the next subsections, together with an assessment of the quality of the technique-specific results. A synthetic overview of the parameters setup in the NEQ systems of each group of observations is presented in Table 1.

\subsection{GNSS analysis and validation}

GNSS observations were processed in double-difference mode using the quasi-ionosphere-free linear combination and setting a cutoff elevation of $3^{\circ}$. Baselines were formed maximizing the number of simultaneous observations recorded by the associated stations. For the sake of consistency, GPS and GLONASS data were processed jointly. The pre-processing phase was carried out on the basis of the analysis strategy developed by the Center for Orbit Determination in Europe (CODE), which is an IGS official Analysis Center (AC) running an operational, fully consistent GPS/GLONASS solution since 2002 (Hugentobler et al. 2006). For both constellations, an attempt was made to fix initial phase ambiguities, following different resolution strategies according to the baseline length, see Dach et al. (2015, chap. 8) for relevant details. This procedure fixed about $80 \%$ of GPS ambiguities, but only $40 \%$ of the GLONASS ones. The asymmetry in the achieved performances is explained by the Frequency Division Multiple Access (FDMA) protocol implemented by the GLONASS system to identify the broadcasting satellite. Unresolved ambiguities were estimated in the final adjustment as float parameters.

Phase center offsets and direction-dependent phase center variations (PCVs) for both satellite and ground antennas were modeled according to the IGS08 ANTEX file (Schmid et al. 2016); satellite z-PCOs were actually set up for each spacecraft and tightly constrained to the $a$ priori values. Antenna radome calibrations and GLONASS-specific models were also accounted for. Concerning atmospheric parameters, second- and higher-order ionospheric terms were modeled according to the strategy of CODE operational solutions; tropospheric zenith path delays, instead, were estimated as a piece-wise linear function sampled every $2 \mathrm{~h}$. In addition, daily horizontal north-south and east-west tropospheric gradients were set up. Orbits were parameterized according to the setting adopted by the CODE AC in the framework of the repro 2 campaign, which constitutes the official IGS contribution to the computation of the ITRF2014.

The quality of the derived solutions was assessed through 7-parameter similarity comparisons with the official IGS repro 2 combined products (Rebischung et al. 2016). The WRMSs of the resulting residuals are displayed in Fig. 2. As it can be seen, if 1-day orbital arcs are set up in the analysis, as recommended by the IGS, the WRMSs of the station position residuals are typically in the order of 2-4 $\mathrm{mm}$ for the horizontal components and of 5-7 $\mathrm{mm}$ for the vertical. Such values are considerably higher than those typically observed for the official IGS ACs over the same time span, usually less than 2 and $5 \mathrm{~mm}$ for the horizontal and vertical components, respectively (Rebischung et al. 2016). For the interpretation of these results, it is important to mention that the presented solution relies on a rather sparse network and encompasses a large amount of GLONASS capable stations in order to strengthen the GNSS-SLR connection via the space-tie approach. Processing GLONASS observations is complicated by the shortcomings of the selected orbital model (Rodriguez-Solano et al. 2014) for highly nonspherical satellites and by limitations in the application of the available algorithms for ambiguity resolution under the FDMA protocol. These issues are long known to affect the quality of the derived products (Meindl 2011), especially in 
Table 1 List of estimated parameters, parameterization choices and applied constraints adopted in the analysis of GNSS measurements (upper block), SLR observations to the LAGEOS satellites (middle block) and SLR observations to GNSS satellites (lower block)

\begin{tabular}{|c|c|c|}
\hline Estimated parameters & Parameterization & Constraints \\
\hline \multicolumn{3}{|c|}{ GNSS-only solutions (9 days) } \\
\hline Station coordinates & 1 set of $3 \mathrm{D}$ coordinates over 9 days & $\begin{array}{l}\text { NNR w.r.t. a priori coordinates } \\
\text { over GNSS reference stations }\end{array}$ \\
\hline \multirow[t]{2}{*}{ EOPs } & $\begin{array}{l}\text { Estimated daily as offset }+ \text { drift: } \\
-\mathrm{X}-, \text { Y-pole coordinates }\end{array}$ & \\
\hline & - UT1-UTC & $\begin{array}{l}\text { Offset heavily constrained to C04 } \\
\text { time series aligned to ITRF08 } \\
\text { (1.E-6 ms) }\end{array}$ \\
\hline \multirow[t]{4}{*}{ Satellite orbits } & $\begin{array}{l}3 \text { non-overlapping orbital arcs of } 3 \text { days. No } \\
\text { connection imposed at the arc boundaries. } \\
\text { Each arc was parameterized as: } \\
6 \text { Keplerian elements at the beginning of the orbital } \\
\text { arc; } \\
5 \text { empirical acceleration parameters }\left(\text { ECOModel }^{\mathrm{a}}\right) \text { : } \\
\text { - Constants in D-, Y- and X-directions } \\
\text { - Periodic } 1 \text { per rev. terms in X-direction; } \\
\text { Velocity breaks every } 12 \mathrm{~h} \text { : }\end{array}$ & \\
\hline & - Radial & 1.E-6 m/s \\
\hline & - Along track & $1 . \mathrm{E}-5 \mathrm{~m} / \mathrm{s}$ \\
\hline & - Out of plane & $1 . \mathrm{E}-8 \mathrm{~m} / \mathrm{s}$ \\
\hline Tropospheric correction & $\begin{array}{l}\text { Zenith wet delays: } \\
\text { - estimated for each station every } 2 \mathrm{~h} \\
\text { - piece-wise linear parameterization } \\
\text { - mapping function: wet } \mathrm{VMF} 1^{\mathrm{b}} \\
\text { Tropospheric gradients: } \\
\text { - N-S and E-W pairs estimated daily for each station } \\
\text { - piece-wise linear parameterization } \\
\text { - mapping function from Chen and Herring (1997) }\end{array}$ & Loose relative constraints of $1 \mathrm{~m}$ \\
\hline Ambiguity & 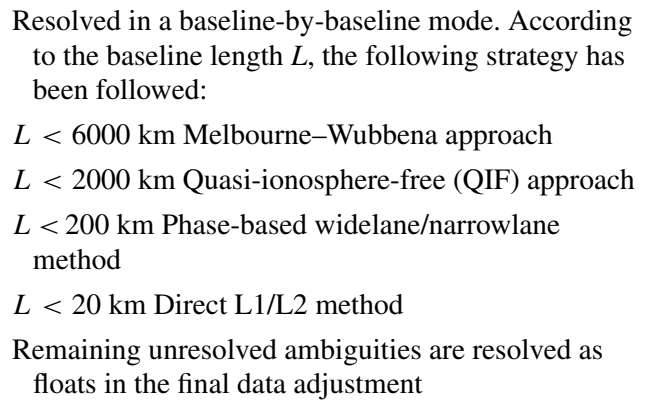 & \\
\hline PCOs & Setup for each individual satellite & $\begin{array}{l}\text { Standard solution: } 1 \mathrm{E}-5 \mathrm{~m} \text { w.r.t. } \\
\text { igs08.atx } \\
\text { Solutions computed for Fig. } 7 \text {, } \\
\text { Tables 4, and 5: free zPCO }\end{array}$ \\
\hline
\end{tabular}


Table 1 continued

\begin{tabular}{|c|c|c|}
\hline Estimated parameters & Parameterization & Constraints \\
\hline \multicolumn{3}{|l|}{ SLR to LAGEOS (7 days) } \\
\hline Station coordinates & 1 set of $3 \mathrm{D}$ coordinates over 7 days & $\begin{array}{l}\text { Loose constraints of } 1 \mathrm{~m} \text { w.r.t. a } \\
\text { priori coordinates (applied in the } \\
\text { derivation of the reference } \\
\text { LAGEOS-only solution) }\end{array}$ \\
\hline EOPs & $\begin{array}{l}\text { Estimated daily: } \\
\text { - X-, Y-pole offset } \\
\text { - UT1-UTC offset + drift }\end{array}$ & $\begin{array}{l}\text { Offset heavily constrained to } \mathrm{C} 04 \\
\text { time series aligned to ITRF08 } \\
\text { (1.E-6ms) }\end{array}$ \\
\hline Satellite orbit parameters & $\begin{array}{l}1 \text { orbital arc of } 7 \text { days parameterized as follows: } \\
6 \text { Keplerian elements at the beginning of the orbital } \\
\text { arc; } \\
5 \text { empirical acceleration parameters: } \\
\text { - Constant in along-track direction } \\
\text { - Periodic } 1 \text { per rev. terms in cross- and along-track } \\
\text { direction; }\end{array}$ & \\
\hline Tropospheric parameters & $\begin{array}{l}\text { Not estimated: Mendes-Pavlis zenith delay model } \\
\text { and mapping function applied }\end{array}$ & \\
\hline Range bias & According to ILRS data handling file & \\
\hline \multicolumn{3}{|l|}{ SLR to GNSS ${ }^{c}$} \\
\hline Station coordinates & $\begin{array}{l}\text { 3D coordinates of SLR stations-stacking } \\
\text { performed at the level C-1 of Fig. } 5\end{array}$ & \\
\hline EOPs & $\begin{array}{l}\text { Same parameterization adopted for the SLR to } \\
\text { LAGEOS solution-stacking performed at the } \\
\text { level A-1 (with GNSS NEQ) and at the level C-1 } \\
\text { (with SLR to LAGEOS NEQ) of Fig. } 5\end{array}$ & \\
\hline Satellite orbit parameters & $\begin{array}{l}\text { Same parameterization adopted for the GNSS-only } \\
\text { solution-stacking performed at the level A-1 of } \\
\text { Fig. } 5\end{array}$ & \\
\hline Tropospheric parameters & $\begin{array}{l}\text { Not estimated: Mendes-Pavlis zenith delay model } \\
\text { and mapping function applied }\end{array}$ & \\
\hline Range bias & $\begin{array}{l}\text { Solution RBilrs: RBs setup for the stations indicated } \\
\text { in the ILRS data handling file for the analysis of } \\
\text { LAGEOS data } \\
\text { Solution RBall: RBs setup for all SLR stations }\end{array}$ & \\
\hline
\end{tabular}

The parameterization indicated in the SLR to GNSS ${ }^{\mathrm{c}}$ block is designed for the combination with GNSS data and SLR observations to LAGEOS satellites; in the entries referred to common parameters, it is made reference to next Fig. 5 in order to specify at which stage of the combination the relevant stacking is performed. The references for the models cited in the table can be found in:

${ }^{a}$ ECOModel, Springer (1999); Beutler et al. (1994); Arnold et al. (2015)

${ }^{b}$ Vienna mapping function VMF1, Boehm et al. (2006)

case of poor spatial coverage. In addition, it shall be pointed out that most of the ACs contributing to the IGS repro2 campaign did not include GLONASS data in their analysis (Rebischung et al. 2016), or, as in the case of CODE, processed much denser networks. In order to cope with these issues, the original daily solutions were turned into 3-day adjustments characterized by the estimation of a single orbital arc and a unique set of station positions. Since the procedure led to a satisfactory reduction of the WRMSs, Fig. 2-red line, 3-day arcs have been adopted for modeling the orbits of GNSS satellites throughout this study, despite the IGS recommendation to process GNSS data daily. This choice impacted the search for a homogeneous sampling of the time series derived from the different types of observations. Since ILRS guidelines prescribe to process LAGEOS data on a weekly basis, it was decided to down-sample the GNSS time series by stacking three consecutive non-overlapping 3-day solutions centered on the ILRS week. As orbit parameters were not included in this step, and the final 9-day solutions were still relying on 3-day orbital arcs. 


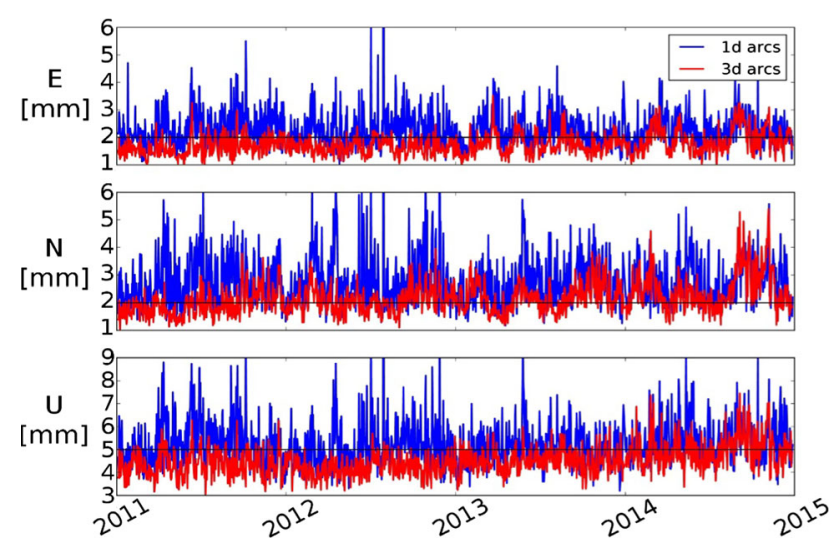

Fig. 2 WRMSs of station position residuals resulting from 7parameter similarity comparisons between our daily (blue line) and 3-day (red line) GNSS solutions and the IGS repro2 combined results. The horizontal black lines indicate the upper limit of the general agreement shown by the solutions provided by the official IGS ACs

Adopting 3-day orbital arcs entails smoothing and overconstraining orbital parameters with reference to official IGS products. As shown in Fig. 2, this approach allows reducing the noise in station positions, implying that the errors affecting the daily POD must have been pushed somewhere else. In recent years, the 3-day arc approach has been investigated by Lutz et al. (2016), who concluded that long-arc computations improve also geocenter and EOPs estimates. In the light of their results and of the correlations existing between the different parameters, errors are then likely to be absorbed by atmospheric delays, clock offsets and/or float ambiguities. However, further investigations are needed in order to draw conclusive remarks.

\subsection{SLR analysis and validation}

As previously mentioned, both SLR observations to the two LAGEOS satellites and to GPS/GLONASS vehicles carrying on-board retroreflector arrays were analyzed in this study. For the first group of data, the ILRS has long-established analysis standards that were followed in the derivation of the presented results; for the second group, instead, no official guidelines have ever been issued. The strategy selected for this project results from a mixture of references to the available literature, e.g., Thaller et al. $(2011,2014)$, and independent choices which will be detailed in the following.

According to ILRS guidelines, SLR measurements to the LAGEOS satellites were processed in weekly batches, including all stations that acquired at least 10 normal points (NPs). Range biases and CoM corrections were set up by following the recommendations of the ILRS Analysis Working Group (AWG) (Mueller and Vei 2016; Otsubo and Appleby 2003). Tropospheric delays were modeled according to Mendes et al. (2002) and Mendes and Pavlis (2004).

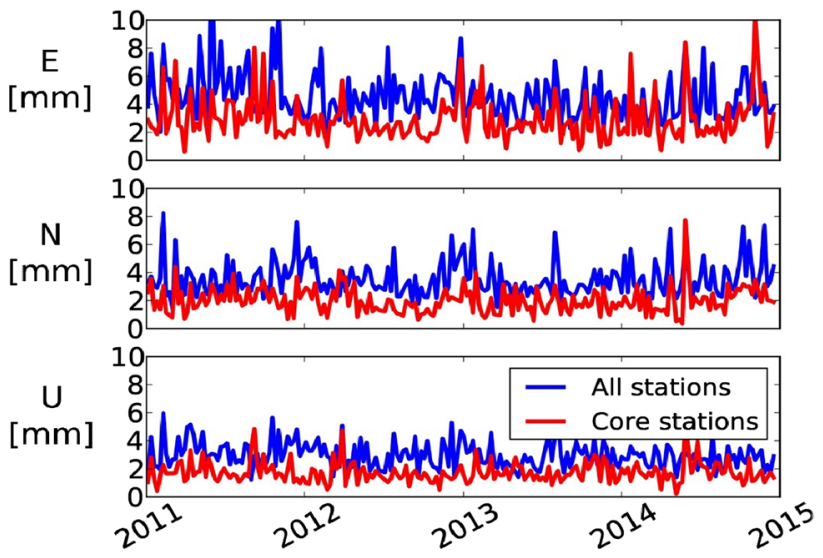

Fig. 3 WRMSs of station position residuals resulting from 7parameter similarity comparisons between our weekly LAGEOS solution and the ILRS official contribution to the computation of the ITRF2014. Results obtained considering either all the available SLR stations or just the core sites are indicated in blue and red, respectively

The orbit parameterization encompassed 6 initial osculating elements, a constant acceleration in the along-track direction, and two once-per-revolution accelerations in the along-track and cross-track directions. A single arc was set up over the entire week.

Similarly to the procedure followed for GNSS estimates, the LAGEOS solution computed for this study was validated against the official ILRS contribution to ITRF2014. The two solution series were compared on a weekly basis, through 7-parameter similarity transformations; the WRMSs of the resulting station position residuals are reported in Fig. 3. Over the investigated 4-year period, such WRMSs are in the order of 4-6 mm for each component. If the computation is restricted to core stations only, the WRMS decreases by a factor of 2 , as a consequence of the significantly better tracking performances achieved by these sites both in terms of data quality and yield. The presented results are comparable to the analogous computations carried out by the official ILRS ACs. It should be pointed out that, contrary to the ILRS official contribution to ITRF2014, SLR data to ETALON satellites have not been included in the study at hand. Even at present, however, observations to these satellites are still largely outnumbered by LAGEOS ones, and their contribution to the official ILRS solution is still marginal (Luceri and Pavlis 2016).

Finally, SLR observations to GPS-35, GPS-36 and all GLONASS satellites were taken into account in order to tie the two techniques via the selected co-location in space. As explained by Thaller et al. (2011), the actual link is realized by the common estimation of orbital parameters with the contribution of both observation types. The same orbit parameterization and the same $a$ priori values adopted for GNSS data were used in the derivation of the normal equation systems. For SLR-specific parameters, on the other hand, 


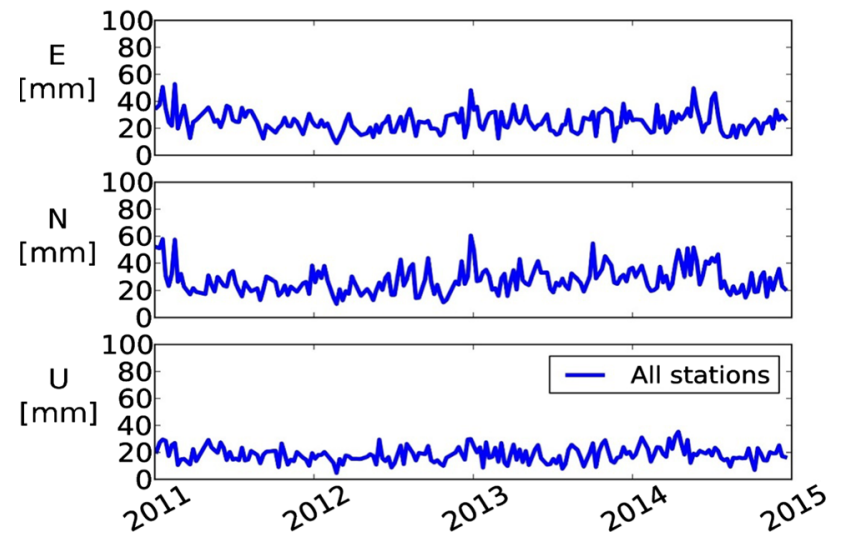

Fig. 4 WRMSs of station position residuals resulting from 7parameter similarity comparisons between 9-day estimates based on SLR observations to GNSS satellites and the weekly ILRS official contribution to the computation of the ITRF2014

dedicated choices were required. In particular, two different solutions were computed: in CASE RBilrs, range biases to GNSS satellites were set up following the ILRS guidelines issued in the framework of the analysis of LAGEOS data; in CASE RBall, they were estimated for all stations. Following the findings of Thaller et al. (2011), RBs were set up in the form of one offset per station and group of satellites. This means that only two RBs were introduced for each SLR site, one for the two GPS spacecrafts, and one for all the GLONASS. Even if, in principle, a satellite-specific dependency could be observed, some of the adjustments performed for this study are carried out at the weekly level and estimating range biases over such short periods considerably increases the noise of the solution, especially for poorly performing stations. It is therefore not convenient to set up one parameter per satellite-station pair, if empirical evidences suggest that this is not strictly necessary. In both analysis types, LRA offsets were kept fixed to the ILRS official values and so possible errors in the tabulated information might be mapped into the range bias parameters. The characteristics of the laser arrays mounted on the different GNSS spacecrafts are available at the ILRS Web site; for a synthetic summary, the reader can refer to Sośnica et al. 2015-Table 3.

Also the solutions based on SLR observations to GNSS satellites were compared to the ILRS official contribution to ITRF2014 through a 7-parameter transformation. It should be pointed out, however, that the SLR tracking of GNSS satellites does not provide enough observations to (reliably) estimate all the parameters on which the observable depends. Therefore, for the purpose of the comparison, a dedicated trial solution was computed estimating only station positions and RBs while fixing GNSS satellite orbits to the a priori values, i.e., to the precise orbits computed by CODE in the framework of the repro2 campaign. The WRMSs of the resulting residuals are presented in Fig. 4. The average agreement is found at the 2-cm level, which is 5 times higher than the case of SLR solutions to LAGEOS satellites when all the active SLR stations are considered.

\subsection{Inter-technique combination}

The inter-technique combination encompassed a series of successive stages, as summarized in Fig. 5. In a first step, all the available information concurring to the estimation of GNSS satellite orbits was merged, maintaining the model detailed in Sect. 3.1 for the GNSS-only solution. The daily NEQ systems set up independently for GNSS data and SLR observations to GNSS satellites for three consecutive days were stacked (Dach et al. 2007, Eq. 9.12) into a unique NEQ system relying on a single orbital arc. The resulting time series was then down-sampled in order to allow the final stage of the combination with the LAGEOS solution. Considering the necessary constraints on the length of the orbital arc, 9-day normal equations centered on the ILRS week were derived from the stacking of three consecutive nonoverlapping 3-day systems. Finally, the overall combination with the LAGEOS information was performed by stacking the normal equations referred to the same mean epoch. As a result, a time series of quasi-instantaneous reference frames was obtained relying exclusively on the technique co-location on-board GNSS satellites.

During the combination, each of the three groups of contributing observations was weighted on the basis of the noise level of the specific adjustments. In particular, weights were computed as the product between the a priori $\sigma$ of unit weight, $\sigma_{0}$, selected in raw data analysis, and the mean of the a posteriori variance factors estimated for the relevant 9-day/weekly solutions. The $\sigma_{0}$ values were set to 1,10 , and $50 \mathrm{~mm}$ for GNSS data and SLR observations to LAGEOS and GNSS satellites, respectively. The corresponding average a posteriori variance factors resulted 1.96, 0.95, and 1.42. It should be pointed out that for SLR observations to GNSS satellites, the mean a posteriori variance factor was evaluated from the inversion of the trial solution with reduced parameterization. As a consequence, the derived weight might be optimistic.

\subsection{Long-term solutions}

The computations described in Sects. 3.1-3.3 produced four different time series:

(1) GNSS-only 9-day time series

(2) LAGEOS-only weekly time series

(3) Quasi-instantaneous 9-day frames derived from the combination of GNSS data and SLR observations to GNSS and to LAGEOS satellites; in this case, two different time series were computed according to the strategy selected 


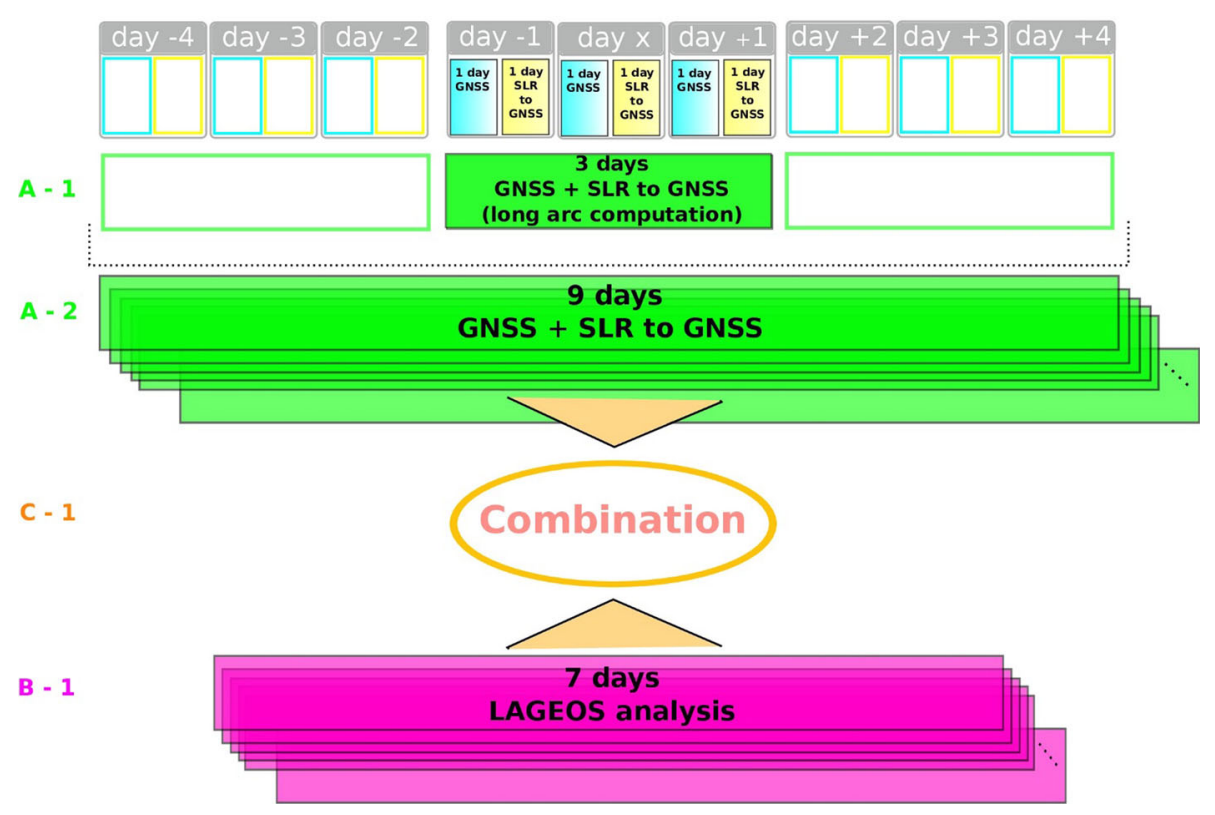

Fig. 5 Flowchart of the inter-technique combination. Branch A: (1) The daily NEQ systems set up independently for GNSS data and SLR observations to GNSS satellites for three consecutive days were stacked by means of the common parameters into a long-arc pre-combined solution; (2) the obtained time series was resampled to weekly comparable

for estimating SLR range biases to GNSS satellites, either case RBilrs or case RBall.

In order to investigate the efficiency of the link provided by the selected space ties on a long-term basis, all these time series have been stacked into long-term solutions according to the model implemented in the CATREF software (Altamimi et al. 2007, 2016). The list of station discontinuities and the post-seismic deformation models applied in the realization of the ITRF2014 were used. The origin and the scale of the cumulated solutions were defined using internal constraints (IC) (Altamimi et al. 2007), while the orientation was specified by minimum constraints (MC) (Altamimi et al. 2008) with reference to ITRF2014.

The long-term stacking of (3) provided the secular realization of the combined reference frame based on the space-tie approach. The stacking of (1) and (2), on the other hand, served as base for a traditional frame computation where terrestrial local ties are needed.

In summary, we formed the following long-term (LT) secular frames:

(LT-1) GNSS-only, constructed by accumulating the corresponding time series

(LT-2) LAGEOS-only, constructed by accumulating the corresponding time series

(LT-3) GNSS-only + LAGEOS-only, constructed by combining the two long-term solutions (LT-1) and (LT-2) time intervals (centered on the SLR week). Branch B: (1) A weekly analysis of SLR observations to LAGEOS satellites was performed according to ILRS recommendations. Branch C: (1) The overall combination was performed stacking A-2 and B-1 normal equations referred to the same mean epoch

together with terrestrial ties. This is, in fact, a traditional ITRF-like combination. In (LT-3), the subset of terrestrial ties used for the realization of ITRF2014 and valid in the interval 2011-2014 was applied. In addition, complying with the ITRF computation strategy, the more reliable origin and scale information realized by LAGEOS observations (Altamimi et al. 2007, 2011) was transferred to the fully combined frame. From the technical point of view, this was realized by setting up transformation offsets and relative rates between the combined solution (which inherits the origin and scale of the SLR to LAGEOS frame) and the input GNSS-only long-term solution.

(LT-4) Fully combined secular frame based on space ties, constructed by accumulating the time series of 9-day frames derived from the combination of GNSS data and SLR observations to GNSS and to LAGEOS satellites. Two variants of long-term solutions were generated: (LT4a) using RBilrs option and (LT-4b) using RBall option.

The two combination approaches (LT-3 and LT-4 summarized above) realized in this study reflect different philosophies for the reference frame definition. When implementing the space-tie approach, in fact, all the available observations are taken into account for the realization of the frame defining parameters. In the ITRF-like process, instead, the realization of origin and scale relies exclusively on LAGEOS data. 
Fig. 6 Translation $(\mathbf{a}, \mathbf{b}, \mathbf{c})$ and scale (d) offsets estimated between the 9-day GNSS-only solutions and the GNSS subnetwork within the fully combined short-term frames (a)

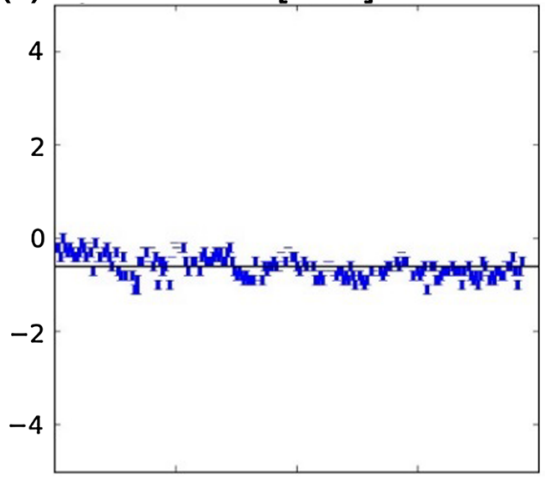

(c)

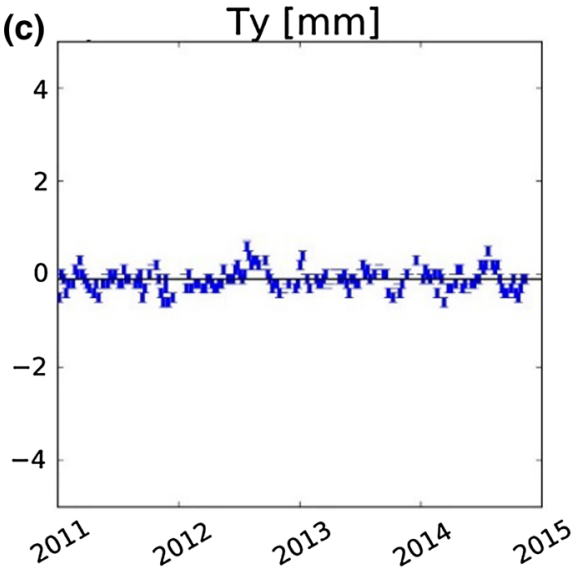

(b)

(b) $\quad \mathrm{Tz}[\mathrm{mm}]$
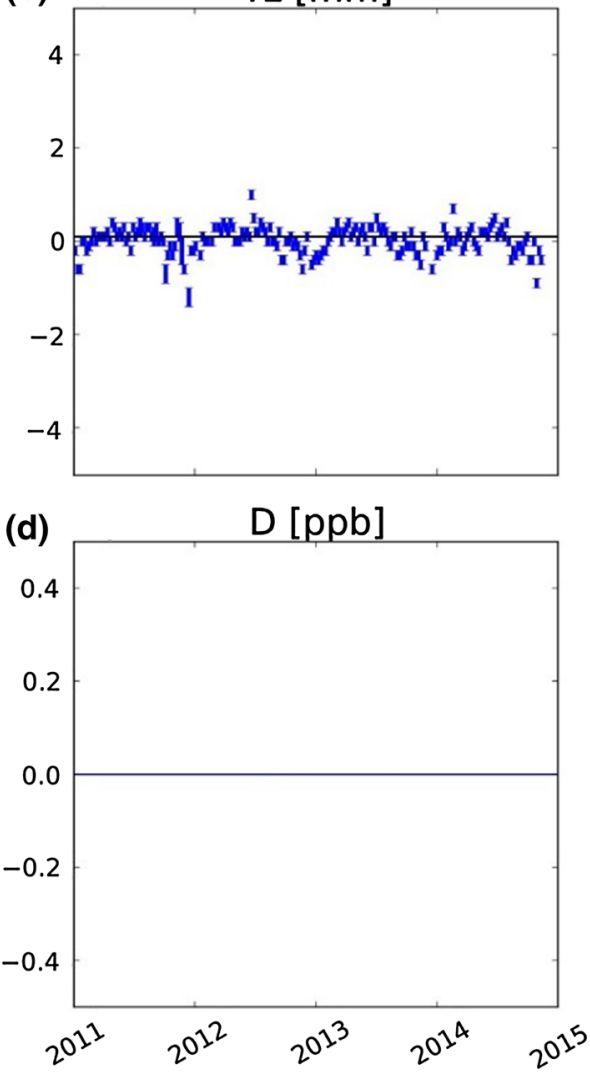

\section{Results}

The linking efficiency of the space ties on-board GNSS satellites was assessed comparing the frame information (origin and scale) realized by each technique-specific solution and the overall combined products. The results of the quasiinstantaneous and of the long-term analyses are presented separately in the following subsections.

\subsection{Quasi-instantaneous approach}

The figures presented in this section show the translation and scale offsets resulting from the comparison of the fully combined short-term frame realizations with the corresponding technique-specific solutions. Figures 6 and 7 refer to the GNSS subnetwork, while Figs. 8 and 9 refer to the SLR one.

Results presented in Fig. 6 show that the frame realized by the GNSS subnetwork in the combined solution is equivalent to the one computed with GNSS data only, at the level of a few tenths of $\mathrm{mm}$. According to the implemented analysis strategy, space ties are, therefore, not conveying any LAGEOS-derived information to the GNSS frame in the combined solution.

Concerning translation offsets, these results aim at complementing previous studies where the space ties on-board

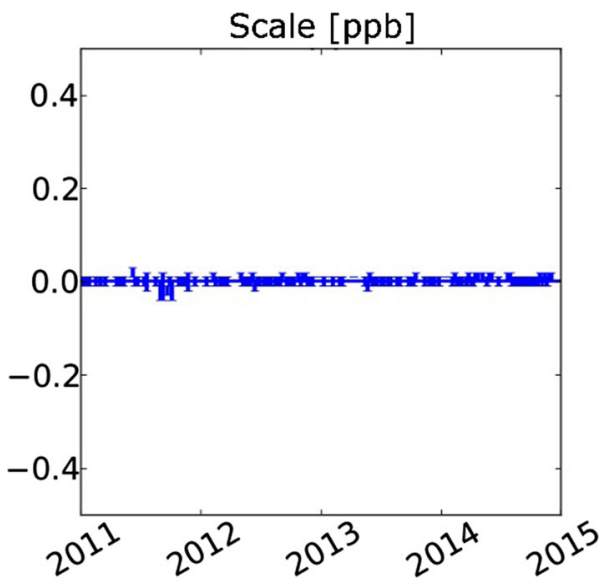

Fig. 7 Scale differences between fully combined short-term frames and GNSS-only 9-day solutions both estimated with free z-PCOs

GNSS satellites were used to combine GNSS and SLR data. In these works, geocenter coordinates were typically estimated as explicit parameters and then discussed in the light of the different scenarios adopted in data analysis. Thaller et al. (2014), for example, explored different constraining options for a subset of orbital parameters, while Thaller et al. (2013) investigated the results of choosing different core networks for the application of no net translation (NNT) constraints. Our study, on the other hand, is concerned with an assessment 
Fig. 8 Translation $(\mathbf{a}, \mathbf{b}, \mathbf{c})$ and scale (d) offsets estimated between the weekly

LAGEOS-only solutions and the SLR subnetwork of the fully combined short-term frames-CASE RBall
Fig. 9 Translation (a,b,c) and scale (d) offsets estimated between the weekly LAGEOS-only solutions and the SLR subnetwork of the fully combined short-term frames-CASE RBilrs
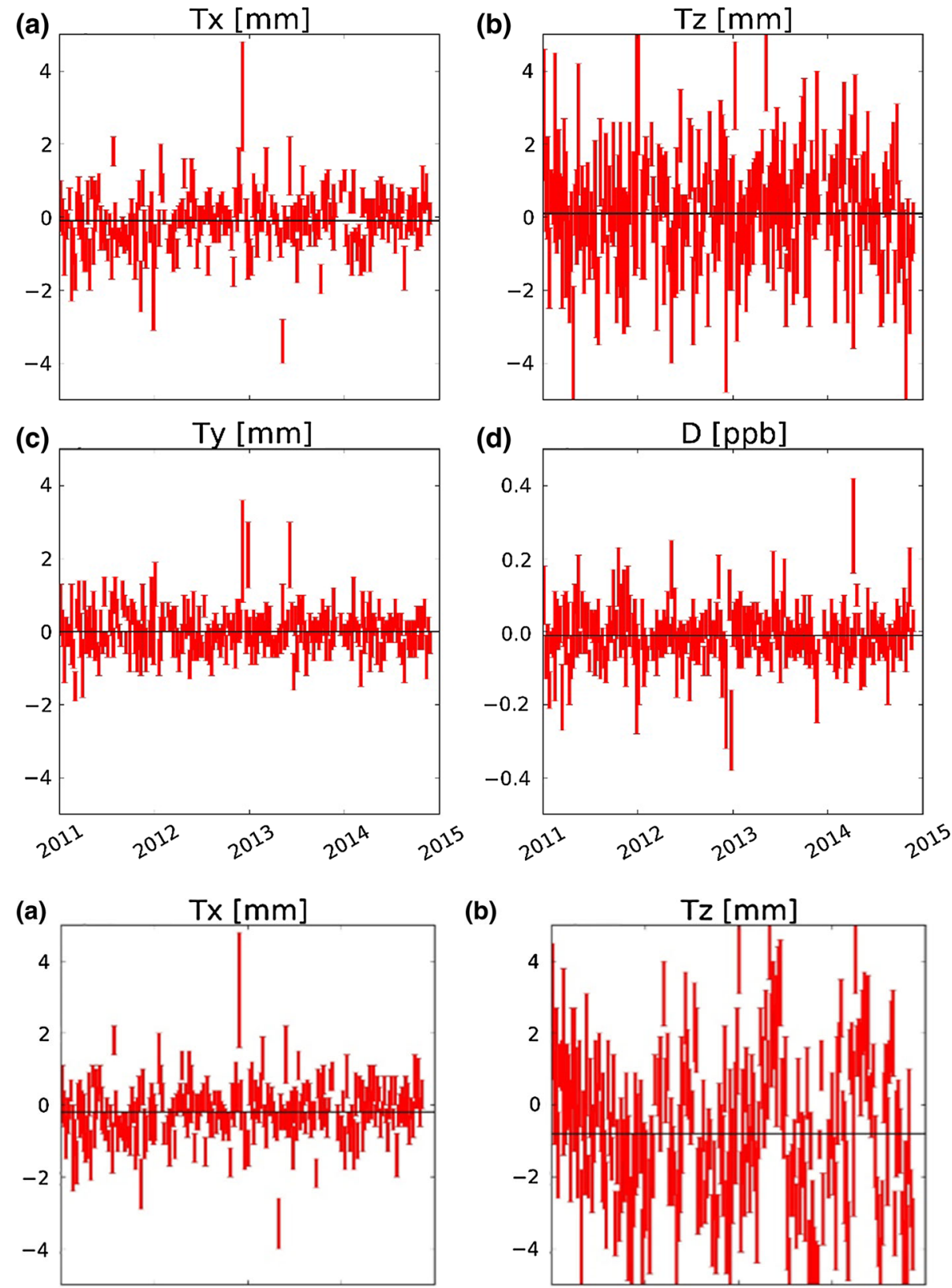

(b)
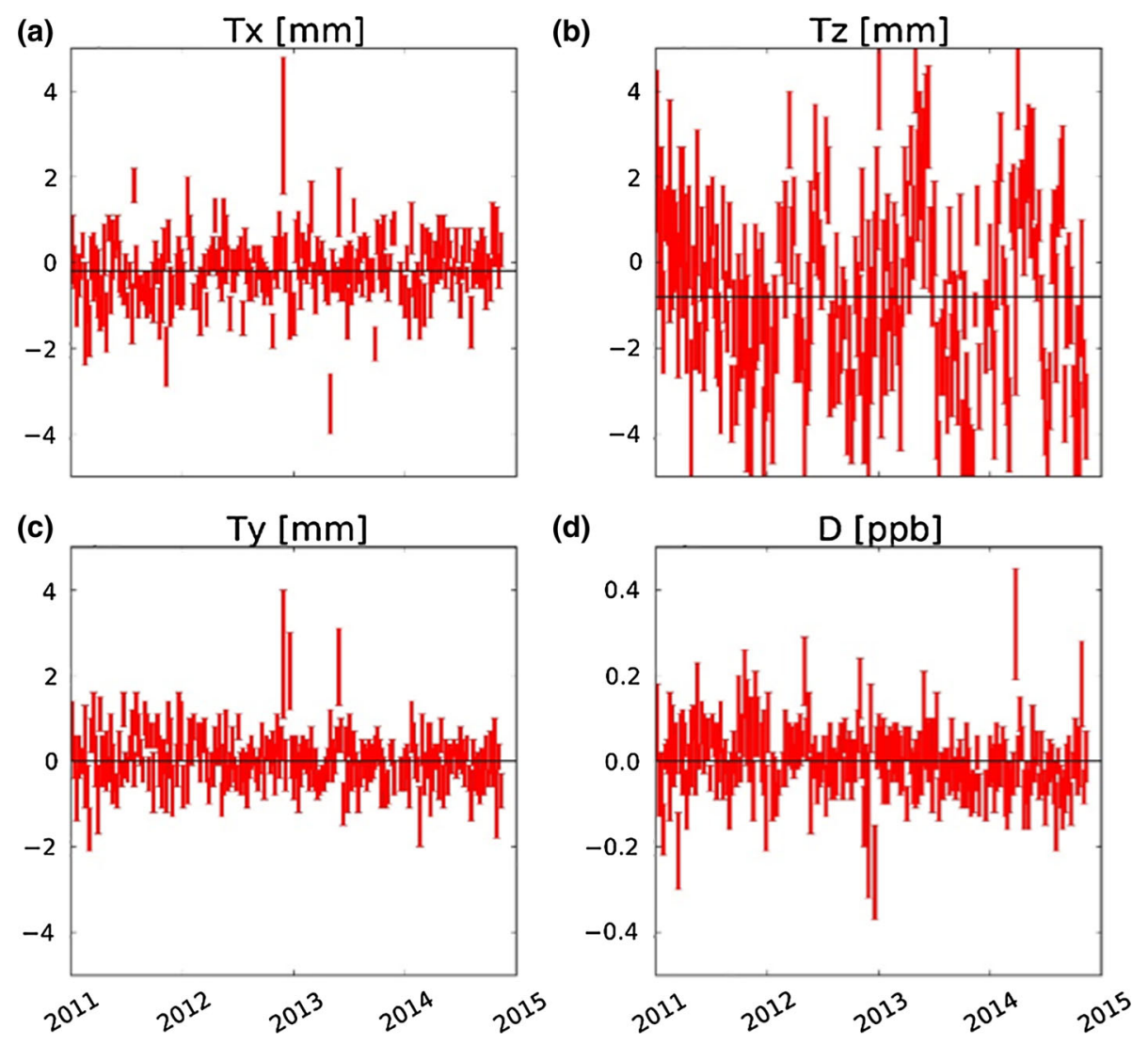
of the homogeneity of the combined frame, i.e., on establishing whether the implemented combination approach realizes a solution in which all the technique-specific subnetworks share the same origin and scale.

The results presented in Fig. $6 \mathrm{a}-\mathrm{c}$ are in line with the conclusions of Rebischung et al. (2014), who linked the GNSS weak sensitivity to geocenter motion to the necessary simultaneous estimation of satellite clock parameters and atmospheric delays in GNSS analyses. SLR observations to GNSS satellites do not depend directly from any of these quantities and, therefore, do not provide any additional information to their estimates. A limited improvement could have been expected for $\mathrm{Tz}$, because of its partial correlation with a subset of the selected orbit parameters (Rebischung 2014). In operational conditions, however, GNSS data are so much more abundant and precise than SLR observations to GNSS satellites that they dominate the orbit estimation process and no detectable effects are found on Tz.

For what concerns Fig. 6d, no differences are visible because, in both solutions, GNSS satellite PCOs were kept fixed to the official IGS08 values, so that the scale of the GNSS network was conventionally defined in both cases. Another computation has then been carried out adding the radial (z) components of the satellite PCOs to the standard parameterization. The estimation of these additional parameters introduces an almost perfect correlation with the scale of the GNSS network. GNSS-only solutions can nevertheless be obtained because the relevant NEQ systems are almost, but not exactly singular, see Rebischung (2014, Fig. 4.3). The realized scale is, however, rather meaningless in this case, as it becomes highly contaminated by modeling errors. In the fully combined solution, it could have been expected that this near-singularity would be overcome by the scale information provided by SLR observations. This would have been the case if the co-location on-board GNSS satellites could offer an efficient link between the two techniques. The scale differences between the fully combined short-term frames and the GNSS-only 9-day solutions with free z-PCOs are presented in Fig. 7. It can be seen that no significant scale differences actually exist between the two solutions. According to the results of our analysis, the selected space ties are not transferring any SLR-based scale information to the GNSS frame, even when GNSS satellite z-PCOs are freely estimated. If the combined solution with free zPCOs is compared to the GNSS-only solution with fixed zPCOs, an average bias of 0.7 $\mathrm{ppb}$ is retrieved, in agreement with the findings of Thaller et al. (2015). We suggest, however, that such offset comes from releasing the constraints on zPCOs rather than from the contribution of LAGEOS data.

No relevant origin or scale discrepancies are observed also when focusing on the SLR subnetwork, as shown in Figs. 8 and 9, referring to CASE RBall and CASE RBilrs solutions, respectively. The time series are considerably nois-
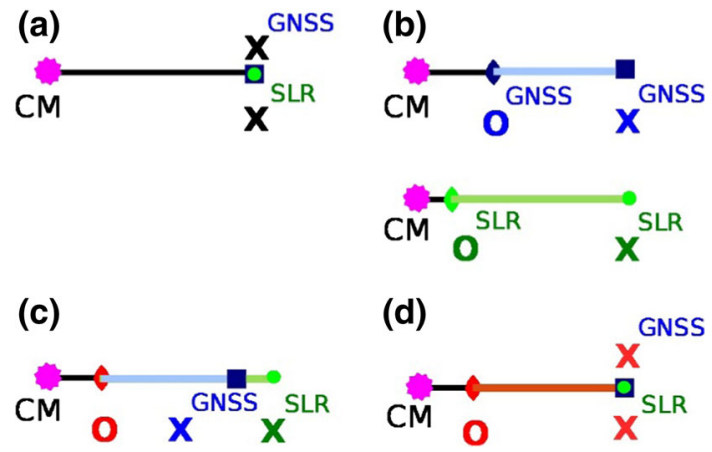

Fig. 10 1D-sketch representation of inter-technique combinations with/without applying effective tying constraints. a Physical situation: Two stations are located at a certain distance $x$ from the center of mass. $\mathbf{b}$ In each system-specific frame, station coordinates depend on the inherent realization of the frame origin and scale. $\mathbf{c}$ When the employed ties fail to actually link the two frames, stations keep positioning according to their own intrinsic frame realization even in the "combined" solution. $\mathbf{d}$ In properly combined frames, instead, all subnetworks adopt the same origin and scale and the spatial co-location of the two stations is restored

ier than in the GNSS case, mainly because of the contribution of SLR observations to GNSS satellites, but no significant mean offsets are observed. It can be noted, however, that discrepancies in $\mathrm{Tz}$ and in the scale are less stable when range biases to GNSS satellites are not routinely estimated for all sites (CASE RBilrs). This is reasonable considering that such parameters absorb modeling errors and inconsistencies which otherwise map into station coordinates.

The presented plots show that, in the combined solution, each technique-specific subnetwork keeps its own independent frame realization. According to the results of the performed analysis, the selected space ties are not providing any actual link, and the two realizations coexist autonomously within the "combined" solution.

A simple one-dimensional sketch is illustrated in Fig. 10 to assist the interpretation of the achieved results. Let us assume that a GNSS and an SLR station are installed at the same distance $\mathrm{x}$ from the geocenter, Fig. 10a. In general, different (biased) realizations of the center of mass and of the scale are materialized in each technique-specific frame. Therefore, the coordinates of the two points in each relevant system may differ from one another even if the stations are physically co-located in the same point, Fig. 10b. The application of effective ties during the combination leads to a unified frame in which all subnetworks rely on the same frame parameters. Due to systematic errors and modeling deficiencies, the materialized origin and scale will still be biased, but the relative positioning of the stations will be correctly reproduced at the expenses of rigid transformations and/or deformations of the original technique-specific networks, Fig. 10d. On the contrary, when the employed ties fail to actually link the two 
Table 2 Transformation parameters estimated at epoch 2010:001 from the GNSS-only long-term solution (LT-1) to the GNSS subnetwork within the different realizations of the combined frames

\begin{tabular}{|c|c|c|c|c|c|c|c|}
\hline Long-term (LT) frame & $\mathrm{Tx}(\mathrm{mm})$ & Ty (mm) & $\mathrm{Tz}(\mathrm{mm})$ & $\mathrm{D}(\mathrm{ppb})$ & $\mathrm{Rx}$ (mas) & Ry (mas) & $\mathrm{Rz}$ (mas) \\
\hline $\begin{array}{r}\text { LT-3 relying on } \\
\text { terrestrial ties }\end{array}$ & $6.3(0.0)$ & $-2.0(0.0)$ & $-0.2(0.0)$ & $-0.55(0.00)$ & $0.000(0.000)$ & $-0.000(0.000)$ & $-0.000(0.000)$ \\
\hline $\begin{array}{l}\text { LT-4a relying on } \\
\text { space ties (case } \\
\text { RBilrs) }\end{array}$ & $-0.2(0.0)$ & $-0.2(0.0)$ & $0.1(0.1)$ & $-0.01(0.00)$ & $0.000(0.001)$ & $0.000(0.001)$ & $0.000(0.001)$ \\
\hline $\begin{array}{l}\text { LT- } 4 \mathrm{~b} \text { relying on } \\
\text { space ties (case } \\
\text { RBall) }\end{array}$ & $-0.4(0.1)$ & $-0.3(0.1)$ & $0.0(0.1)$ & $-0.01(0.00)$ & $0.000(0.001)$ & $0.000(0.001)$ & $0.000(0.001)$ \\
\hline
\end{tabular}

Uncertainties are indicated within brackets; when uncertainties are reported as equal to 0 , it means that they are smaller than the last displayed digit

Table 3 Transformation parameter rates estimated from the GNSS-only long-term solution (LT-1) to the GNSS subnetwork within the different realizations of the combined frames

\begin{tabular}{|c|c|c|c|c|c|c|c|}
\hline Long-term (LT) frame & $\mathrm{T}^{\prime} \mathrm{x}(\mathrm{mm} / \mathrm{y})$ & T'y $(\mathrm{mm} / \mathrm{y})$ & $\mathrm{T}^{\prime} \mathrm{z}(\mathrm{mm} / \mathrm{y})$ & $\mathrm{D}^{\prime}(\mathrm{ppb} / \mathrm{y})$ & $\mathrm{R}^{\prime} \mathrm{x}(\mathrm{mas} / \mathrm{y})$ & R'y (mas/y) & $\mathrm{R}^{\prime} \mathrm{z}$ (mas/y) \\
\hline $\begin{array}{r}\text { LT-3 relying on } \\
\text { terrestrial ties }\end{array}$ & $-0.1(0.0)$ & $0.1(0.0)$ & $0.6(0.0)$ & $-0.02(0.00)$ & $0.004(0.000)$ & $0.020(0.000)$ & $-0.006(0.000)$ \\
\hline $\begin{array}{l}\text { LT-4a relying on } \\
\text { space ties (case } \\
\text { RBilrs) }\end{array}$ & $0.0(0.0)$ & $0.1(0.0)$ & $0.0(0.0)$ & $0.00(0.00)$ & $0.000(0.000)$ & $0.000(0.000)$ & $0.000(0.000)$ \\
\hline $\begin{array}{l}\text { LT-4b relying on } \\
\text { space ties (case } \\
\text { RBall) }\end{array}$ & $-0.1(0.0)$ & $0.1(0.0)$ & $0.0(0.0)$ & $0.00(0.00)$ & $0.000(0.000)$ & $0.000(0.000)$ & $0.000(0.000)$ \\
\hline
\end{tabular}

Uncertainties are indicated within brackets; when uncertainties are reported as equal to 0 , it means that they are smaller than the last displayed digit

frames, the origin and scale information of the individual contributions is not homogenized and, even within the final "combined" solution, stations keep positioning according to their own intrinsic frame realization, Fig. 10c. According to the results shown in Figs. 6, 7, 8, and 9, this is the case for the space ties on-board GNSS satellites.

\subsection{Long-term approach}

The performance of the GNSS-SLR space ties on-board GNSS satellites has been further tested on the basis of the computation of secular reference frames. The quality of the tying approach was assessed evaluating the similarity between the combined frame with the technique-specific long-term solutions. In particular, the investigation aimed at identifying whether, under the different tying approaches, the origin and the scale of the GNSS subnetwork within the combined frames benefited from the contribution of the SLR observations to LAGEOS satellites. For this purpose, the transformation parameters and rates estimated between the combined frames and the long-term GNSS-only solution are shown in Tables 2 and 3, respectively.

These results reflect the weakness of the investigated space link. In general, in fact, independent solutions can be adjusted in a combined product only at the expenses of a certain deformation of the input contributions (see Fig. 10d). When the space-tie approach is followed in the combination, however, the GNSS subframe does not show any significant difference with respect to its original input contribution. Values reported in Tables 2 and 3 show that, when the space-tie approach is followed, SLR observations to LAGEOS satellites do not provide any contribution to the origin and scale materialized by the GNSS subnetwork within the combined solution. The origin and scale differences retrieved between the compared solutions are, in fact, at the submillimeter level, confirming that the GNSS-only subnetwork keeps its own frame realization within the combined solution.

When the terrestrial tie approach is followed, on the other hand, discrepancies arise in both the origin and the scale realization. Per se, this is not a conclusive indication that a perfectly homogeneous reference frame is realized by the application of terrestrial ties, but it provides an evidence that some origin and scale information is transferred from one subnetwork to the other. It can be noted that the stable scale offset of $-0.55 \mathrm{ppb}$ is consistent with the official ITRF2014 realization (Altamimi et al. 2016, Fig. 9), where the scale is computed as the average of the SLR and VLBI contributions. According to Appleby et al. (2016), such offset shall be attributed to the estimation of RBs to LAGEOS satellites only for a limited subset of stations and is likely to be considerably reduced by estimating RBs for the whole tracking network. 
Table 4 Transformation parameters estimated at epoch 2010:001 from the GNSS-only long-term solution (LT-1, with free zPCOs) to the GNSS subnetwork within the combined frame implementing the space-tie approach (case RBilrs) when, in both solutions, GNSS zPCOs were set free

\begin{tabular}{llllllll}
\hline Long-term (LT) frame & $\mathrm{Tx}(\mathrm{mm})$ & $\mathrm{Ty}(\mathrm{mm})$ & $\mathrm{Tz}(\mathrm{mm})$ & $\mathrm{D}(\mathrm{ppb})$ & $\mathrm{Rx}(\mathrm{mas})$ & $\mathrm{Ry}(\mathrm{mas})$ & $\mathrm{Rz}(\mathrm{mas})$ \\
\hline $\begin{array}{l}\text { LT-4a relying on } \\
\text { space ties free }\end{array}$ & $-0.1(0.1)$ & $-0.1(0.1)$ & $0.0(0.2)$ & $-0.00(0.09)$ & $0.002(0.009)$ & $-0.002(0.009)$ & $0.002(0.008)$ \\
GNSS zPCOs & & & & & & \\
\hline
\end{tabular}

Uncertainties are indicated within brackets

Table 5 Transformation parameter rates estimated from the GNSS-only long-term solution (LT-1, with free zPCOs) to the GNSS subnetwork within the combined frame implementing the space-tie approach (case RBilrs) when, in both solutions, GNSS zPCOs were set free

\begin{tabular}{lllllllll}
\hline Long-term (LT) frame & T'x (mm/y) & T'y (mm/y) & T'z (mm/y) & D' (ppb/y) & R'x (mas/y) & R'y (mas/y) & R'z (mas/y) \\
\hline LT-4a relying on space ties free GNSS zPCOs & $0.0(0.0)$ & $0.0(0.0)$ & $0.0(0.1)$ & $0.00(0.00)$ & $0.000(0.001)$ & $0.001(0.001)$ & $-0.001(0.001)$
\end{tabular}

Uncertainties are indicated within brackets; when uncertainties are reported as equal to 0 , it means that they are smaller than the last displayed digit

Table 6 Characteristics of the different simulated cases

\begin{tabular}{llll}
\hline ID & N of SLR stations & $\sigma_{0}^{\text {SLR to LAG }(\mathrm{mm})}$ & $\sigma_{0}^{\text {SLR to GNSS }}(\mathrm{mm})$ \\
\hline A25 & 25 & 10 & 50 \\
A49 & 49 & 10 & 50 \\
B25 & 25 & 10 & 10 \\
B49 & 49 & 10 & 10 \\
C25 & 25 & 1 & 5 \\
C49 & 49 & 1 & 5 \\
D25 & 25 & 1 & 1 \\
D49 & 49 & 1 & 1 \\
\hline
\end{tabular}

The presented results do not depend on the estimation of RBs to GNSS satellites, even if SLR observations to these satellites are likely to be biased for virtually all the stations (Otsubo et al. 2001; Thaller et al. 2011). In this context, the performed long-term stacking allowed estimating multi-year values for the range biases. For most of the stations, however, the resulting RBs to the GNSS satellites were not statistically significant, as the associated uncertainties were of the same magnitude as the biases themselves. For this reason, the estimated RBs were considered of too poor quality to be back substituted in the original NEQ systems. The values retrieved for the RBs to LAGEOS satellites, on the other hand, were consistent with the average of the yearly results presented in Appleby et al. (2016) over the period 2011-2014. It must be noted, however, that RBs to LAGEOS satellites were set up in this study following the current ILRSs prescriptions and that Appleby et al. (2016) presented only the results achieved for the best performing stations. Therefore, the comparison was limited to 4 sites only: 7403, 7810, 8834, and 7249 for which RB estimates resulted $14(4), 8.0(0.8),-5(2)$, and $0(6)$ $\mathrm{mm}$, respectively.

Finally, the proposed comparison has been performed for the solutions with free zPCOs introduced in Sect. 4.1. The resulting transformation parameters and their rates are reported in Tables 4 and 5, respectively. Also in that case, however, the selected space ties did not transfer any frame, and particularly any scale, information to the GNSS subnetwork.

\section{Simulations}

Results presented in Sect. 4 show that, at present, the implemented combination strategy is insufficient to replace the use of terrestrial ties. The investigated co-locations in orbit are, however, particularly appealing for the computation of the ITRF, as they directly link two of the four contributing systems. In principle, the proposed tying approach might even support the investigation of technique-specific biases, improving the accuracy of the derived results. For these reasons, multiple simulations were run in order to establish whether improvements in tracking performances might strengthen the provided connection and eventually realize a reliable inter-technique bond.

For that purpose, we simulated different daily sets of GNSS and SLR observations, in which the abundance and quality of the SLR data were progressively increased. A combined normal matrix was built for each simulated scenario, following the same parameterization as in our standard analysis, except that GNSS phase ambiguities were all assumed to be fixed. Each normal matrix was then inverted under appropriate minimal constraints, so as to obtain the variance- 

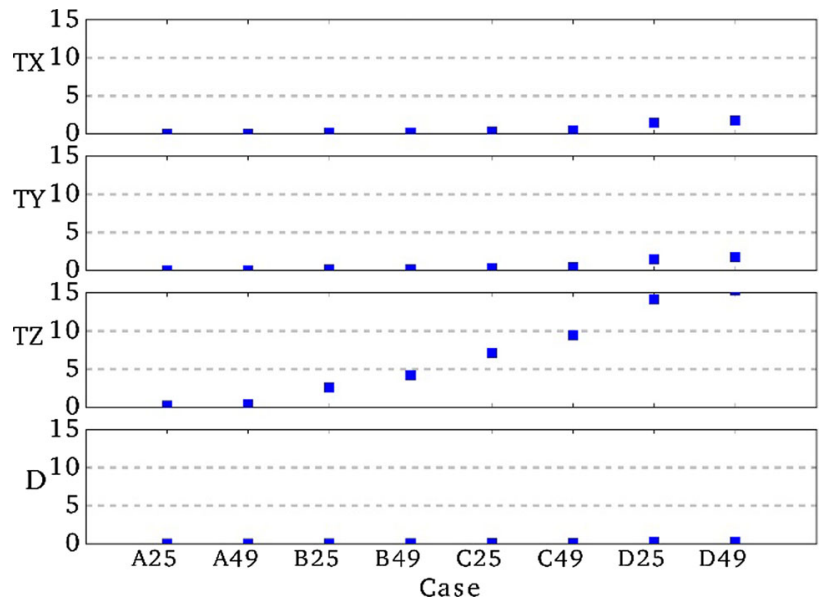

Fig. 11 Relative reduction of the formal errors of the origin and scale of the GNSS network within the combined solution with respect to the GNSS-only reference simulation. The characteristics of the displayed cases are detailed in Table 6

covariance matrix of the estimated parameters derived from each observation set. In the following, we will only focus on the uncertainties (formal errors) thus obtained for the origin and the scale of the GNSS network in the different scenarios. A GNSS-only simulation was also performed to serve as a reference.

The simulations encompassed the three groups of data considered throughout this study: GNSS measurements and SLR observations to LAGEOS and GNSS satellites. For all spacecrafts, nominal orbit specifications were adopted. All GNSS vehicles were considered equipped with SLR retroreflectors. A perfectly homogeneous distribution of the ground networks was implemented for both techniques, ignoring the actual partitioning between oceans and inland areas. The GNSS network was composed of 100 stations, the SLR one of either 25 or 49 depending on the simulated scenario. Notwithstanding the acquired data type, the same observation rate of $5 \mathrm{~min}$ was adopted for all stations. This assumption is far from being realistic for SLR, especially concerning day-time acquisitions and/or high targets such as GNSS satellites, but it guarantees a wealth of information even on a daily basis. The precision of GNSS observations was kept fixed to $1 \mathrm{~mm}$ level, while the different possibilities explored for SLR are listed in Table 6. Starting values of $\sigma_{0}^{\text {SLRtoLAG }}=1 \mathrm{~cm}$ and $\sigma_{0}^{\text {SLRtoGNSS }}=5 \mathrm{~cm}$ were gradually reduced until a very optimistic scenario where all SLR observations were considered as precise as the GNSS measurements. For each simulation, Fig. 11 shows the reduction of the formal errors of the origin and scale realized by the GNSS subnetwork within the combined solution relatively to the GNSS-only reference case.

Apart from the z-component of the geocenter, the formal errors of the GNSS frame parameters are barely affected by the addition of SLR data. In the most optimistic investigated scenario, i.e., when the same precision is assumed for all data types, the improvement in $\mathrm{Tz}$ is about $15 \%$. This component, however, is the least well determined by GNSS measurements (Rebischung et al. 2014), and the observed improvement only partially copes for the gap observed between the precision of $\mathrm{Tz}$ and that of $\mathrm{Tx}$ and $\mathrm{Ty}$ in the GNSS-only simulation (about 20\%). Focusing on the cases referred to the state-of-the-art precision (A25 and A49), Fig. 11 shows that no significant effect is observed even considering a large network of highly performing stations. In this context, it should be pointed out that the minimum SLR network dimension selected in these simulations, 25 stations, can be considered as an upper limit for the number of sites currently included in the weekly adjustments of LAGEOS observations (Sośnica et al. 2014, Fig. 2). In real conditions, however, the network distribution is strongly inhomogeneous and only a limited subnetwork of about 10-15 sites reaches high tracking performances.

An additional set of simulations was performed freeing z-PCOs. Also in this case, the highest impact was observed for $\mathrm{Tz}$ when assuming a 1-mm precision for all data types. No effects were observed for the other frame parameters and most notably for the scale.

The modest improvements observed are consistent with the evidence that the GNSS weak ability to sense the geocenter (and the scale) depends primarily on collinearity issues related to the simultaneous estimation of tropospheric and clock parameters (and z-PCOs). None of these quantities, however, is included in the SLR observation equation, which means that SLR measurements do not provide any direct information to their determination. On the other hand, the partial correlation of $\mathrm{Tz}$ with orbit parameters explains why this component is the one for which the greatest effects are observed.

\section{Conclusions}

The co-location of different geodetic techniques on-board orbiting satellites offers the attractive opportunity to link their independent networks while overcoming some of the most problematic aspects of the terrestrial ties currently used for the computation of the ITRF, namely their spatial distribution and the frequency of their updates. Nevertheless, the actual strength of the provided link has to be thoroughly investigated in order to characterize the precision and the accuracy of the combined frame parameters. In this work, the co-location of the GNSS and SLR techniques on-board GNSS satellites has been investigated at different timescales, revealing that, at present, this linking approach is not suitable to replace terrestrial ties in the derivation of homogeneous combined reference frames. According to our results, the provided link is, in fact, unable to transfer any scale or origin information from one subnetwork to the other. 
At the weekly level, it has been shown that the independent subnetworks maintain their technique-specific origin and scale realization within the solution resulting from the investigated combination approach. In particular, the GNSS origin and scale do not benefit from the combination with LAGEOS observations which provide a more accurate materialization of the frame parameters. Even when z-PCOs are freed, bringing the estimation of the GNSS scale on the verge of instability, the two technique frames remain distinct and just coexist within the merged solution. A theoretical justification of this behavior can be found in the mechanism that drives the GNSS materialization of the frame physical parameters. The GNSS limited sensitivity to geocenter motion (and scale) depends on the simultaneous estimation of clock parameters, atmospheric delays (and satellite PCOs), none of which is directly impacted by SLR observations. These results were also confirmed by our long-term analysis that showed that the GNSS frame realization within the combined solution did not benefit from the combination with SLR observations to LAGEOS data.

It must be stressed that the actual realization of the space-tie approach investigated in this study reckons on SLR observations to GNSS satellites. Since such data are currently limited in number and considerably noisier than GNSS data and SLR observations to LAGEOS satellites, it was additionally studied whether significant improvements in the availability and quality of laser ranges to GNSS satellites would have an impact on the effectiveness of the investigated space-tie approach. A simulation study was run in order to retrieve the formal errors associated with the GNSS frame parameters under different observing scenarios. The simulations assumed a perfectly distributed network of high performing SLR stations acquiring a valid return every 5 min during each satellite flyover. Under the best investigated conditions, i.e., when the same tracking precision was implemented for all the involved groups of observations, a precision improvement of about $15 \%$ was found for $\mathrm{Tz}$, while the other frame parameters were basically not impacted. The observed effects are rather modest especially considering the technological and infrastructural gap between the state-ofthe-art tracking conditions and the implemented scenarios.

In the light of the achieved results, the presented combination strategy relying on the co-location of the GNSS and SLR techniques on-board GNSS satellites does not provide, at present, a viable tying approach for the realization of a homogeneous combined terrestrial reference frame. Even improvements in the quality and abundance of the SLR tracking of GNSS satellites are likely to have just a limited impact in the near future. The most relevant contribution of SLR measurements to GNSS vehicles remains the microwaveindependent orbit validation process.

In a broader context, this study highlights the importance of a deep understanding of the mechanisms driving the sensitivity of each geodetic technique to the reference frame parameters. Concerning the investigated link, in fact, SLR observations cannot directly sense any of the quantities controlling the GNSS sensitivity to the physical frame parameters, thus severely limiting the efficiency of the investigated co-location in orbit.

Acknowledgements This work was performed under grant ECOCZE RB from the Università di Bologna. ILRS and IGS are kindly acknowledged for providing the original data. The authors would like to thank the anonymous reviewers for their valuable comments and suggestions which contributed to improving the quality of the manuscript.

\section{References}

Altamimi Z, Collilieux X, Legrand J, Garayt B, Boucher C (2007) ITRF2005: a new release of the international terrestrial reference frame based on time series of station positions and earth orientation parameters. J Geophys Res Solid Earth. doi:10.1029/ 2007JB004949

Altamimi Z, Collilieux X, Boucher C (2008) Accuracy assessment of the ITRF datum definition. In: Xu P, Liu J, Dermanis A (eds) VI Hotine-Marussi symposium on theoretical and computational geodesy. Springer, Berlin, pp 101-110. doi:10.1007/978-3-64222078-4

Altamimi Z, Collilieux X, Metivier L (2011) ITRF2008: an improved solution of the international terrestrial reference frame. J Geod 85(8):457-473. doi:10.1007/s00190-011-0444-4

Altamimi Z, Rebischung P, Métivier L, Collilieux X (2016) ITRF2014: a new release of the international terrestrial reference frame modeling nonlinear station motions. J Geophys Res Solid Earth 121:6109-6131. doi:10.1002/2016JB013098

Appleby G, Rodríguez J, Altamimi Z (2016) Assessment of the accuracy of global geodetic satellite laser ranging observations and estimated impact on ITRF scale: estimation of systematic errors in LAGEOS observations 1993-2014. J Geod 90:1371-1388. doi:10. 1007/s00190-016-0929-2

Arnold D, Meindl M, Beutler G et al (2015) CODE's new solar radiation pressure model for GNSS orbit determination. J Geod 89:775. doi:10.1007/s00190-015-0814-4

Beutler G, Brockmann E, Gurtner W, Hugentobler U, Mervart L, Rothacher M, Verdun A (1994) Extended orbit modeling techniques at the CODE processing center of the international GPS service for geodynamics (IGS): theory and initial results. Manuscr Geod 19:367-384

Blewitt G (2015) Terrestrial reference frame requirements for studies of geodynamics and climate change. In: IAG Symposium Springer, Berlin, pp 1-8. doi:10.1007/1345_2015_142

Blewitt G, Altamimi Z, Davis JL, Gross R, Kuo C-Y, Lemoine FG, Moore AW, Neilan RE, Plag H-P, Rothacher M, Shum CK, Sideris MG, Schöne T, Tregoning P, Zerbini S (2010) Geodetic observations and global reference frame contributions to understanding sea-level rise and variability. In: Church J, Woodworth PL, Aarup $\mathrm{T}$, Wilson $\mathrm{S}$ (eds) Understanding sea-level rise and variability. Wiley, Chichester, pp 256-284. ISBN 978-1-443-3451-7

Boehm J, Werl B, Schuh H (2006) Troposphere mapping functions for GPS and very long baseline interferometry from European Centre for Medium-Range Weather Forecasts operational analysis data. $\mathrm{J}$ Geophys Res 111:B02406. doi:10.1029/2005JB003629

Chen G, Herring TA (1997) Effects of atmospheric azimuthal asymmetry on the analysis of space geodetic data. J Geophys Res 102:20489-20502. doi:10.1029/97JB01739 
Dach R, Hugentobler U, Fridez P, Meindl M (eds) (2007) Bernese GPS software version 5.0. user manual. Astronomical Institute, University of Bern, Bern

Dach R, Lutz S, Walser P, Fridez P (2015) Bernese GNSS software version 5.2. user manual. Astronomical Institute, University of Bern, Bern Open Publishing. doi:10.17892/boris.72297. ISBN: 978-3906813-05-9

Dow JM, Neilan RE, Rizos C (2009) The international GNSS service in a changing landscape of global navigation satellite systems. J Geod 83:191-198. doi:10.1007/s00190-008-0300-3

General Assembly of the United Nations Resolution 69/266 (26 February 2015) A global geodetic reference frame for sustainable development, A/RES/69/266

Hugentobler U, Meindl M, Beutler G, Bock H, Dach R, Jäggi A, Urschl C, Mervart L, Rothacher M, Schaer S, Brockmann E, Ineichen D, Wiget A, Wild U, Weber G, Habrich H, Boucher C (2006) CODE IGS analysis center technical report 2003/2004. In: Gowey K, Neilan R, Moore A (eds) IGS 2004 technical reports. IGS Central Bureau

IERS Conventions Center (2015) Updates to the IERS conventions (2010). http://webtai.bipm.org/iers/convupdt/convupdt.html

Luceri V, Pavlis E (2016) The ILRS contribution to ITRF2014. http:// itrf.ensg.ign.fr/ITRF_solutions/2014/doc/ILRS-ITRF2014-descr iption.pdf

Lutz S, Meindl M, Steigenberger P, Beutler G, Sośnica K, Schaer S, Dach R, Arnold D, Thaller D, Jäggi A (2016) Impact of the arc length on GNSS analysis results. J Geod 90(4):365-378. doi:10. 1007/s00190-015-0878-1

Meindl M (2011) Combined analysis of observations from different global navigation satellite systems. PhD thesis GeodätischgeophysikalischeArbeiten in der Schweiz, vol 83

Mendes V, Pavlis EC (2004) High-accuracy zenith delay prediction at optical wavelengths. Geoph Res Lett 31:L14602. doi:10.1029/ 2004GL020308

Mendes V, Prates G, Pavlis EC, Pavlis DE, Langley RB (2002) Improved mapping functions for atmospheric refraction correction in SLR. Geophys Res Lett. doi:10.1029/2001GL014394

Minster JB, Altamimi Z, Blewitt G, Carter WE, Cazenave A, Dragert H, Herring TA, Larson KM, Ries JC, Sandwell DT, Wahr JM, Davis JL (2010) Precise geodetic infrastructure: national requirements for a shared resource. The National Academies Press, Washington, DC, p 142. ISBN 10-309-15811-7

Mueller H, Vei M (2016) ILRS SINEX file with data handling recommentations. http://ilrs.dgfi.tum.de/fileadmin/data handling/ILRS_Data_Handling_File.snx

Nerem RS, Chambers DP, Choe C, Mitchum GT (2010) Estimating mean sea level change from the TOPEX and Jason altimeter missions. Mar Geod 33(S1):435-446. doi:10.1080/01490419.2010. 491031

Otsubo T, Appleby GM (2003) System-dependent center-of-mass correction for spherical geodetic satellites. J Geophys Res Solid Earth. doi:10.1029/2002JB002209

Otsubo T, Appleby GM, Gibbs P (2001) GLONASS laser ranging accuracy with satellite signature effect. Surv Geophys 22(56):509-516. doi:10.1023/A:1015676419548

Pearlman MR, Degnan JJ, Bosworth JM (2002) The international laser ranging service. Adv Space Res 30:135-143. doi:10.1016/S02731177(02)00277-6
Petit G, Luzum B (2010) IERS conventions. In: Petit G, Luzum B (eds) Frankfurt am Main: Verlag des Bundesamts für Kartographie und Geodäsie, 2010. ISBN 3-89888-989-6

Rebischung P (2014) Can GNSS contribute to improving the ITRF definition? Dissertation, Observatoire de Paris

Rebischung P, Altamimi Z, Springer T (2014) A collinearity diagnosis of the GNSS geocenter determination. J Geod 88(1):65-85. doi: 10 . 1007/s00190-013-0669-5

Rebischung P, Altamimi Z, Ray J, Garyat B (2016) The IGS contribution to ITRF2014. J Geod 90(7):611-630. doi:10.1007/s00190-0160897-6

Rodriguez-Solano C, Hugentobler U, Steigenberger P, Bloßfeld M, Fritsche M (2014) Reducing the draconitic errors in GNSS geodetic products. J Geod 88(6):559-574. doi:10.1007/s00190-0140704-1

Sarti P, Abbondanza C, Altamimi Z (2013) Local ties and co-location sites: some considerations after the release of ITRF2008. In: Altamimi Z, Collilieux X (eds) Reference frames for applications in geosciences. Springer, Berlin, pp 75-80. doi:10.1007/978-3642-32998-2_13

Schmid R, Dach R, Collilieux X, Jäggi A, Schmitz M, Dilssner F (2016) Absolute IGS antenna phase center model igs08.atx: status and potential improvements. J Geod 90(4):343-364. doi:10.1007/ s00190-015-0876-3

Sośnica K, Jäggi A, Thaller D, Beutler G, Dach R (2014) Contribution of Starlette, Stella, and AJISAI to the SLR-derived global reference frame. J Geod 88(8):789-804. doi:10.1007/s00190-014-0722-z

Sośnica K, Thaller D, Dach R, Steigenberger P, Beutler G, Arnold D, Jäggi A (2015) Satellite laser ranging to GPS and GLONASS. J Geod 89:725-743. doi:10.1007/s00190-015-0810-8

Thaller D (2008) Inter-technique combination based on homogeneous normal equation systems including station coordinates. Earth orientation and troposphere parameters. Scientific technical report STR 08/15, DeutschesGeoForschungsZentrum Potsdam, ISSN 1610-0956. doi:10.2312/GFZ.b103-08153

Thaller D, Dach R, Seitz M, Beutler G, Mareyen M, Richter B (2011) Combination of GNSS and SLR observations using satellite co-locations. J Geod 85(5):257-272. doi:10.1007/s00190-0100433-z

Thaller D, Roggenbuck O, Sośnica K, Steigenberger P, Mareyen M, Baumann C, Dach R, Jäggi A (2013) SLR-GNSS analysis in the framework of the ITRF2013 computation. In: Proceedings of the 18th international workshop on laser ranging, Fujiyoshida, Japan. https://cddis.nasa.gov/lw18/docs/papers/Session1/13-0105-Thaller.pdf

Thaller D, Sośnica K, Dach R, Jäggi A, Beutler G, Mareyen M, Richter B (2014) Geocenter coordinates from GNSS and combined GNSSSLR solutions using satellite co-locations. In: Rizos C, Willis P (eds) Earth on the edge: science for a sustainable planet. Springer, Berlin, pp 129-134. doi:10.1007/978-3-642-37222-3_16

Thaller D, Sośnica K, Steigenberger P, Roggennbuck O (2015) Precombined GNSS-SLR solutions what could be the benefit for the ITRF? In: van Dam T (ed) REFAG 2014. IAGSymp, vol 146. Springer, Cham, pp 85-94. doi:10.1007/1345_2015_215 